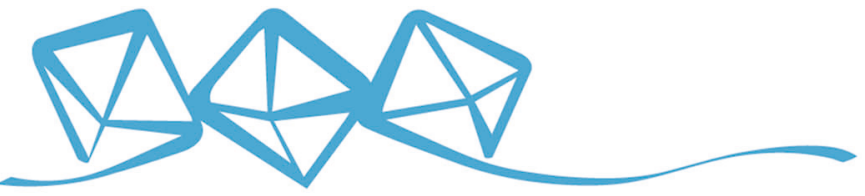 COMMUNICATIONS MATERIALS
}

ARTICLE

https://doi.org/10.1038/s43246-020-00080-4 OPEN

\section{Redox-structure dependence of molten iron oxides}

\author{
Caijuan Shi ${ }^{1,2}$, Oliver L. G. Alderman ${ }^{3,4}$, Anthony Tamalonis ${ }^{3}$, Richard Weber ${ }^{2,3}$, Jinglin You ${ }^{1} \&$ \\ Chris J. Benmore (i) ${ }^{2 凶}$
}

The atomic structural arrangements of liquid iron oxides affect the thermophysical and thermodynamic properties associated with the steelmaking process and magma flows. Here, the structures of stable and supercooled iron oxide melts have been investigated as a function of oxygen fugacity and temperature, using x-ray diffraction and aerodynamic levitation with laser heating. Total $x$-ray structure factors and their corresponding pair distribution functions were measured for temperatures ranging from $1973 \mathrm{~K}$ in the stable melt, to $1573 \mathrm{~K}$ in the deeply supercooled liquid region, over a wide range of oxygen partial pressures. Empirical potential structure refinement yields average $\mathrm{Fe}-\mathrm{O}$ coordination numbers ranging from $\sim 4.5$ to $\sim 5$ over the region $\mathrm{FeO}$ to $\mathrm{Fe}_{2} \mathrm{O}_{3}$, significantly lower than most existing reports. Ferric iron is dominated by $\mathrm{FeO}_{4}, \mathrm{FeO}_{5}$ and $\mathrm{FeO}_{6}$ units in the oxygen rich melt. For ferrous iron under reducing conditions $\mathrm{FeO}_{4}$ and $\mathrm{FeO}_{5}$ units dominate, in stark contrast to crystalline FeO.

\footnotetext{
${ }^{1}$ State Key Laboratory of Advanced Special Steel, Shanghai Key Laboratory of Advanced Ferrometallurgy, School of Materials Science and Engineering, Shanghai University, Shanghai, China. ${ }^{2}$ X-Ray Science Division, Advanced Photon Source, Argonne National Laboratory, Argonne, IL, USA. ${ }^{3}$ Materials Development, Inc, Arlington Heights, IL, USA. ${ }^{4}$ Now at ISIS Facility, Rutherford Appleton Laboratory, Chilton, Didcot Oxon OX11 OQX, UK.

凶email: benmore@anl.gov
} 
$\mathrm{M}$ olten iron oxide plays a crucial role in iron, steel, and copper production ${ }^{1,2}$ and has a major role in determining the behavior and properties of magmatic liquids $^{3-6}$. Iron redox has previously been studied in multicomponent silicate liquids and glasses $3,7,8$, where the oxidation states and coordination numbers have a direct effect on melt viscosity, density, phase stability, and heat capacity ${ }^{7}$. However, the assignment of the local $\mathrm{Fe}$ coordination environment and its relationship to the oxidation state is not straightforward. This is because iron redox depends on many factors, including oxygen partial pressure, temperature, and composition. Wilke ${ }^{7}$ has pointed out that the Fe coordination by oxygen in widely studied glass analogues is likely to differ from those found in high temperature melts. Consequently, the structural role of $\mathrm{Fe}$ is poorly understood due to the difficulty of studying liquids at high temperatures using direct methods 9 . Under oxidizing conditions, no suitable containers exist, and oxygen pressures of several atmospheres or supercooling are essential to stabilize molten $\mathrm{Fe}_{2} \mathrm{O}_{3}$. To our knowledge, the only structural measurements on a pure iron oxide melt are two 40-year-old X-ray diffraction studies by Waseda et al. ${ }^{10,11}$ at compositions close to $\mathrm{FeO}$, and two X-ray absorption near edge studies ${ }^{12,13}$.

Structural interpretation of experimental data is complicated by the fact that both ferrous $\left(\mathrm{Fe}^{2+}\right)$ and ferric $\left(\mathrm{Fe}^{3+}\right)$ iron co-exist in melts, and both can be in a range of coordination environments. $\mathrm{Fe}^{2+}$ is the most abundant iron species in magmas and is usually 6 -fold in crystalline minerals at ambient pressure. In the liquid state however, it has been debated if $\mathrm{Fe}^{2+}$ is primarily 5- or 6-fold coordinated by oxygen ${ }^{14,15}$ or 4 -fold ${ }^{9,16}$. Historically $\mathrm{Fe}^{2+}$ was considered as being distributed between sites coordinated by either 4 or 6 oxygen atoms based on crystal structures ${ }^{16,17}$. However, it has also been suggested that $\mathrm{Fe}$ in the melt, similar to $\mathrm{Al}$, can also be 5 -fold coordinated by oxygen ${ }^{8,18}$. This has been supported by the fact that in some minerals $\mathrm{Fe}-\mathrm{O}$ polyhedra exist with 5-short bonds ${ }^{5}$. A bimodal distribution between 4- and 6fold $\mathrm{Fe}^{2+}$ in molten $\mathrm{FeO}$ would be in contrast to other mixed coordination oxide melts, such as $\mathrm{Al}_{2} \mathrm{O}_{3}, \mathrm{TiO}_{2}$ or $\mathrm{MgO}$, in which liquids and glasses contain a single distribution of metal-oxygen bond distances, representing a mixture of 4,5 , and 6 coordinated units ${ }^{19,20}$. The coordination environment of $\mathrm{Fe}^{3+}$ is similarly unclear. In crystalline $\mathrm{Fe}_{3} \mathrm{O}_{4}, \varepsilon-\mathrm{Fe}_{2} \mathrm{O}_{3}$, and $\gamma-\mathrm{Fe}_{2} \mathrm{O}_{3}, \mathrm{Fe}$ atoms reside mainly in octahedral coordination with some tetrahedral sites. Contrastingly, in a soda-lime-silica glass $\mathrm{Fe}^{3+}$ has been considered to be tetrahedrally surrounded by oxygen atoms, along with minority higher coordination environments ${ }^{21}$, while measurements on $\mathrm{Fe}^{3+}$ in aluminosilicates indicate primarily 5- or 6fold coordination in the liquid state ${ }^{15,16}$, implying considerable compositional dependence.

Here we have determined the structures of liquid $\mathrm{FeO}_{x}(1.0 \lesssim x$ $\lesssim 1.5)$ over a wide range of oxidation states and temperatures, using a combination of aerodynamic levitation with laser heating in various gas mixtures and high-energy X-ray diffraction. Levitation methods enable access to the oxidizing and metastable regions of the $\mathrm{Fe}-\mathrm{O}$ phase diagram without interference from crucible materials, as well as the ability to supercool the liquid by the elimination of heterogeneous crystal nucleation caused by a container. Atomistic models have been obtained using Empirical Potential Structure Refinement (EPSR) modeling, see Table 1. The local Fe-O coordination number in $\mathrm{FeO}_{x}$ melts is found to have majority populations of 4- and 5-fold polyhedra across a wide range of oxidation states, with structures that are very different from the crystalline phases. At the same time, the new data highlights gaps in our understanding of the structural role of iron, even in the pure $\mathrm{FeO}_{x}$ system.

\begin{tabular}{|c|c|c|c|}
\hline & Coulomb charges (e) & $\varepsilon(\mathrm{kJ} / \mathrm{mole})$ & $\sigma(\AA)$ \\
\hline $\mathrm{Fe}^{3+}$ & +1.5 & 0.15 & 1.7 \\
\hline $\mathrm{Fe}^{2+}$ & +1.0 & 0.15 & 1.65 \\
\hline $\mathrm{O}^{2-}$ & -1.0 & 0.1625 & 3.6 \\
\hline
\end{tabular}

We note that $\mathrm{X}$-ray diffraction cannot readily distinguish between $\mathrm{Fe}^{2+}$ and $\mathrm{Fe}^{3+}$ and the $\mathrm{Fe}^{2+}$ parameters have not been widely tested in the literature.

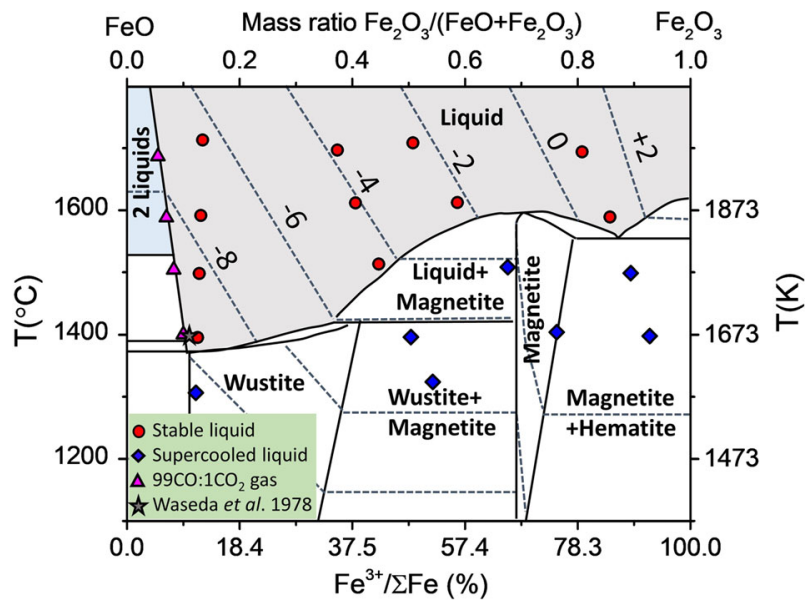

Fig. 1 The $\mathrm{FeO}_{-} \mathrm{Fe}_{2} \mathrm{O}_{3}$ region of the equilibrium phase diagram ${ }^{22}$. The crystalline regions are in white, the single-phase liquid regions in grey and two liquid region in blue. Dashed lines are oxygen isobars labelled with $\log _{10} p\left(\mathrm{O}_{2}\right)$ (atm.). Circles and diamonds represent measurement conditions in this study and the star is the data point from Waseda et al. ${ }^{10}$. Our measurements in $\mathrm{O}_{2}$ gas are plotted to the right of the $10^{0}=1 \mathrm{~atm} . \mathrm{O}_{2}$ line, because equation 12 of ref. ${ }^{35}$ used to calculate $\mathrm{Fe}^{3+} / \Sigma \mathrm{Fe}$ differs slightly from the most recent phase diagram ${ }^{22}$ (see uncertainty discussion and Supplementary Fig. S9). For measurements taken in the most reducing gas mixture $\left(99 \mathrm{CO}: 1 \mathrm{CO}_{2}\right)$ the dome boundary between the oxide liquid and mixed metal + oxide region was used to determine the sample compositions (pink triangles).

\section{Results}

The $\mathrm{FeOx}$ phase diagram. The locations of our liquid $\mathrm{FeO}_{x} \mathrm{X}$-ray measurements within the $\mathrm{FeO}-\mathrm{Fe}_{2} \mathrm{O}_{3}$ region of the phase diagram $^{22}$ are shown in Fig. 1. At temperatures of $\sim 1673 \mathrm{~K}$ and below, the more oxidized liquids are deeply supercooled into the Wustite-Magnetite-Hematite phase fields. The $\mathrm{x}$-ray data at $\sim 1973 \mathrm{~K}$ traverse the entire stable single-phase oxide liquid region. Our most reducing gas atmosphere $\left(99 \mathrm{CO}: 1 \mathrm{CO}_{2}\right)$ is expected to bring the sample within the large miscibility gap between the liquid oxide and metal, however, buoyancy effects lead to measurement of the oxide melt portion only, see Supplementary Figs. S1 and S2 in the high energy X-ray experiments section for a detailed discussion.

X-ray pair distribution functions. We have considered the X-ray pair distribution functions of $\mathrm{FeO}_{x}$ melts, to be composed of six partial pair distribution functions: $\mathrm{Fe}^{2+}-\mathrm{Fe}^{2+}, \mathrm{Fe}^{2+}-\mathrm{Fe}^{3+}, \mathrm{Fe}^{3+}$ $\mathrm{Fe}^{3+}, \mathrm{Fe}^{2+}-\mathrm{O}, \mathrm{Fe}^{3+}-\mathrm{O}$, and $\mathrm{O}-\mathrm{O}$ correlations. In the $D(r)$ of Fig. 2, the intensity of the first peak representing the Fe-O bonds 

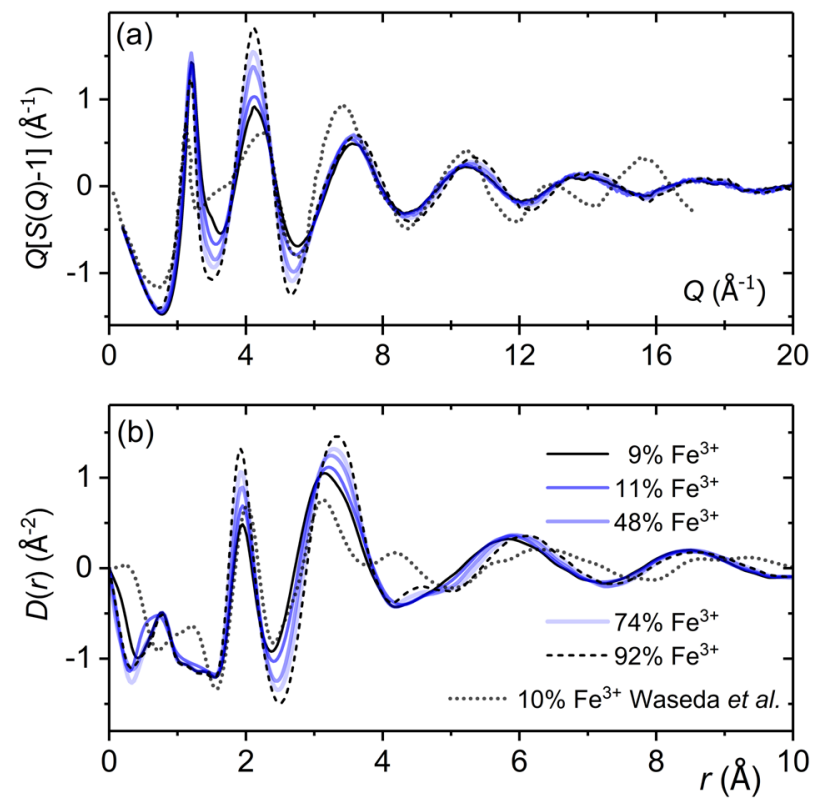

Fig. 2 High energy $X$-ray diffraction data on liquid $\mathbf{F e O}_{\mathbf{x}}$. a $\mathrm{Q}$-multiplied $\mathrm{X}$ ray structure factors $Q[S(Q)-1]$ and corresponding $\mathbf{b}$ differential distribution functions $D(r)$ for liquid $\mathrm{FeO}_{x}$ measured at $\sim 1673 \mathrm{~K}$ in different gases. Comparison is made to the digitized $x$-ray $S(Q)$ from Waseda et al..$^{10}$ and our Fourier transform of this data (dotted lines).

decreases from the most oxidizing to the most reducing atmosphere, and the peak position increases from 1.92(1) $\AA$ to 1.95(1) $\AA$ (Fig. 2). This indicates that on average the $\mathrm{Fe}^{2+}-\mathrm{O}$ bond lengths are longer (and weaker) than $\mathrm{Fe}^{3+}-\mathrm{O}$. Concomitantly, the second peak in $D(r)$ shifts from 3.34(3) $\AA$ to 3.15(2) $\AA$ with a decrease of intensity, which is attributed to changes in the relative amounts of $\mathrm{Fe}^{2+}-\mathrm{Fe}^{2+}, \mathrm{Fe}^{2+}-\mathrm{Fe}^{3+}$ and $\mathrm{Fe}^{3+}-\mathrm{Fe}^{3+}$ neighbors which each have different pair distances. In evaluating the local $\mathrm{Fe}-\mathrm{O}$ coordination numbers, the method of choice of cut-off distance was typically found to shift the absolute values of $n_{\mathrm{FeO}}$ by \pm 0.5 , but did not affect the trend observed and plotted in Fig. 3. Here we define three criteria for the cut-off distance (i) the first minimum in $g_{i j}(r)$ (ii) first minimum in $r^{2} g_{i j}(r)$ and (iii) a fixed value, where the $\mathrm{Fe}^{2+}-\mathrm{O}$ and $\mathrm{Fe}^{3+}-\mathrm{O}$ radial cut-off distances were chosen separately, see Supplementary Figs. S3-S5 in the extraction of coordination numbers section. The $\mathrm{Fe}-\mathrm{O}$ coordination number was obtained using all three methods, and the average $n_{\mathrm{FeO}}$, was determined as a function of $\mathrm{Fe}^{3+} / \Sigma \mathrm{Fe}$, and is shown in Fig. 3a.

EPSR modeling. In our EPSR models, which represent best fits of 3 -dimensional atomic arrangements at the expected densities that reproduce our experimental data, $n_{\mathrm{FeO}}$ is typically found to increase from $\sim 4.3(3)$ at $5.0 \% \mathrm{Fe}^{3+}$ to $5.1(3)$ at $92 \% \mathrm{Fe}^{3+}$. The values of $n_{\mathrm{FeO}}$ as a function of $\mathrm{Fe}^{3+} / \Sigma \mathrm{Fe}$ extracted from $1973 \mathrm{~K}$ to $1573 \mathrm{~K}$ are similar, indicating no temperature dependence within experimental error, except perhaps for the most reduced melts, where $n_{\mathrm{FeO}}$ tends to increase slightly with temperature decreasing. The values of $n_{\mathrm{FeO}}$ concur with previous findings on liquid iron oxide and silicate liquids and glasses obtained from XANES ${ }^{13,18}$, although linear extrapolations used for mixed valence $\mathrm{FeO}_{x}$ to infer endmember $n_{\mathrm{FeO}}$ appear to be inaccurate. Our results differ from early diffraction studies on compositions close to molten $\mathrm{FeO}$, where Waseda et al..$^{10}$ have reported an $\mathrm{Fe}-\mathrm{O}$ peak position of $2.06 \AA$ and $n_{\mathrm{FeO}}=5.5$ at $1673 \mathrm{~K}$ using X-ray diffraction in a dry Argon atmosphere, and $r_{\mathrm{FeO}}=2.16 \AA$ and $n_{\mathrm{FeO}}=5.7$ at 1693 $\mathrm{K}$ using anomalous $\mathrm{X}$-ray scattering ${ }^{11}$. A re-analysis of the Waseda et al. ${ }^{10}$ diffraction data through direct Fourier

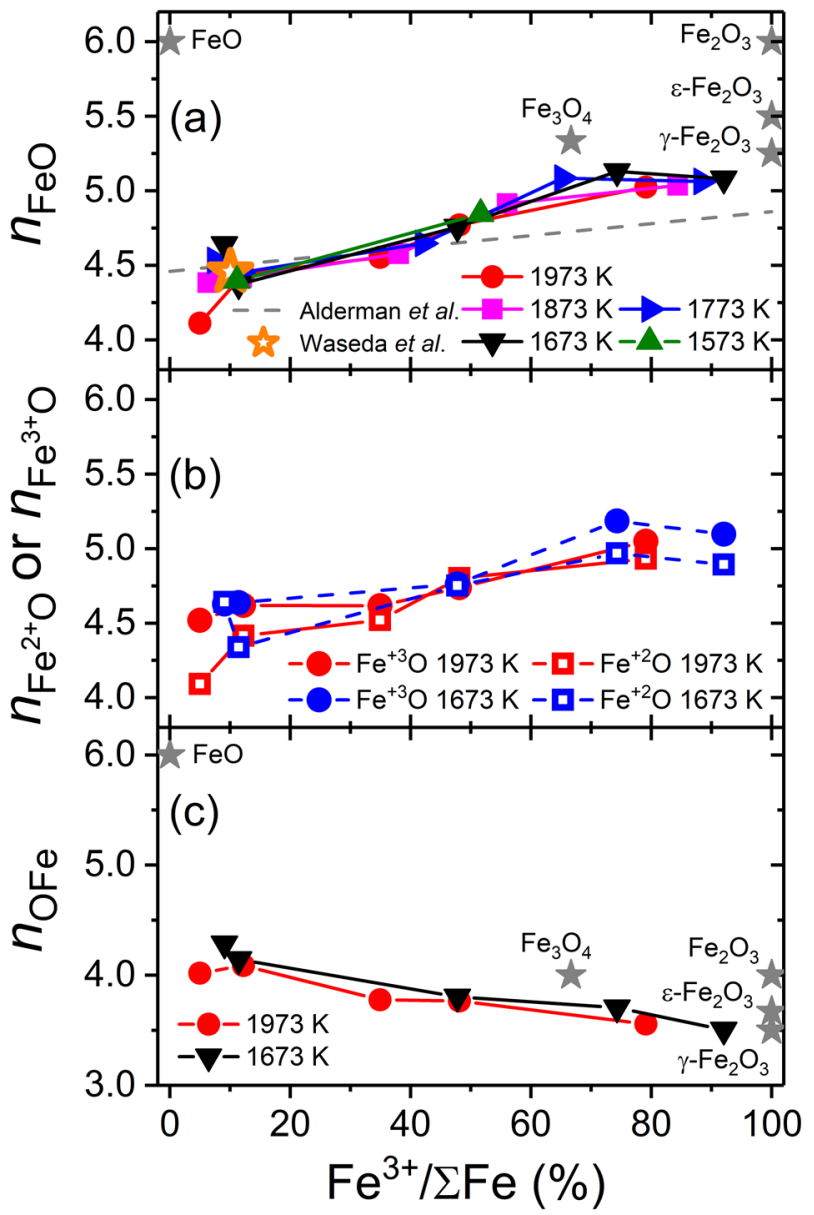

Fig. 3 Coordination numbers from the empirical potential structure refinement fits. a Average $\mathrm{Fe}-\mathrm{O}$ coordination number $\mathrm{n}_{\mathrm{FeO}}$ in molten $\mathrm{FeO}_{x}$ at $1973 \mathrm{~K}, 1873 \mathrm{~K}, 1773 \mathrm{~K}, 1673 \mathrm{~K}$, and $1573 \mathrm{~K}$ (colored symbols) from our EPSR models, as a function of $\mathrm{Fe}^{3+} / \Sigma \mathrm{Fe}$. $n_{\mathrm{FeO}}$ was determined by the average of three cut-off criteria. The solid gray stars represent crystalline iron oxides. $n_{\mathrm{FeO}}$ obtained by reanalyzing Waseda's data ${ }^{10}$ is shown as the open orange star. $n_{\mathrm{FeO}}$ in molten $\mathrm{Fe}_{2} \mathrm{SiO}_{4+x} 25$ is indicated by the dashed line, as derived from peak fitting to $\mathrm{X}$-ray diffraction data, which may lead to a smaller effective radial cut-off than used herein. $\mathbf{b}$ Average $n_{\mathrm{Fe} 2+\mathrm{O}}$ (open squares) and $n_{\mathrm{Fe} 3+\mathrm{O}}$ (solid circles) in molten $\mathrm{FeO}_{x}$ at $1973 \mathrm{~K}$ (red) and 1673 $\mathrm{K}$ (blue). c Average O-Fe coordination number $n_{\mathrm{OFe}}$ in molten $\mathrm{FeO}_{x}$ at 1973 $\mathrm{K}$ (red circles) and $1673 \mathrm{~K}$ (black triangles) from our EPSR models. The estimated error bars are $\pm 10 \mathrm{Fe}^{3+} / \Sigma \mathrm{Fe}(\%)$ and \pm 0.25 on the $n_{\mathrm{FeO}}$ or \pm 0.25 $\left(c_{\mathrm{Fe}} / \mathrm{C}_{\mathrm{O}}\right)$ for $n_{\mathrm{OFe}}$.

transformation of the digitized $S(Q)$ and EPSR modeling reveals $n_{\mathrm{FeO}}=4.6(4)$, in line with our findings. In addition, we note that $n_{\mathrm{FeO}} \approx 5$ for our most oxidized melt $\left(92 \% \mathrm{Fe}^{3+}\right)$ approaches that found in the crystalline form of $\gamma-\mathrm{Fe}_{2} \mathrm{O}_{3}$, despite substantial differences in populations of 4-, 5- and 6-fold Fe-O polyhedra.

\section{Discussion}

Although we obtain Fe-O coordination numbers in reducing atmospheres that are substantially lower than the octahedral coordination found in Wustite, our measurements are in good agreement with first principles molecular dynamics (MD) calculations in related liquid systems (but none have yet been performed on $\left.\mathrm{FeO}_{\mathrm{x}}\right)$. For example, it is found that $n_{\mathrm{Fe} 2+-\mathrm{O}}=4.5$ in $\mathrm{FeMg}_{3} \mathrm{O}_{4}$ (Holmström et al. ${ }^{20}$ ) and $n_{\mathrm{Fe} 2+-\mathrm{O}}=4.9$ in $\mathrm{Fe}_{2} \mathrm{SiO}_{4}$ (Ramo and Stixrude ${ }^{23}$ ). A similar average structure has been predicted for liquid $\mathrm{MgO}$ using ab initio $\mathrm{MD}^{19,24}\left(n_{\mathrm{MgO}}=4.6\right)$ 
Table. 2 A summary of $\mathrm{Fe}^{2+}-\mathrm{O}$ coordination numbers obtained from our MD simulations on FeO using various published pair potentials, compared to our EPSR model with the lowest value of $\mathrm{Fe}^{3+} / \Sigma \mathrm{Fe}$.

\begin{tabular}{|c|c|c|c|c|c|c|}
\hline Material & $\begin{array}{l}\text { EPSR, experimental data or our } \\
\text { Classical MD with pair potential } \\
\text { source cited }\end{array}$ & $T(K)$ & $\boldsymbol{n}_{\mathrm{Fe} 2}+\mathrm{o}$ & $\begin{array}{l}\text { Cut-off distance }(\AA)- \\
\text { average of three } \\
\text { criteria }\end{array}$ & $\begin{array}{l}\text { Atom number } \\
\text { density } \\
\left.\text { (atoms } \AA^{-3}\right)^{29}\end{array}$ & $\begin{array}{l}\text { Mass density } \\
\left(\mathrm{g} \mathrm{cm}^{-3}\right)\end{array}$ \\
\hline $\mathrm{FeO}_{x}$ melt $\left(5.0 \% \mathrm{Fe}^{3+}\right)$ & EPSR & 1960 & 4.24 & 2.83 & 0.0756 & 4.511 \\
\hline $\mathrm{CaFeSi}_{2} \mathrm{O}_{6}$ glass & Rossano EXAFS 44 & RT & 3.90 & 2.6 & - & - \\
\hline $\mathrm{FeO}$ melt & Teter 42 & 2000 & 5.15 & 3.06 & 0.0743 & 4.434 \\
\hline FeO melt & Rossano 44 & 2100 & 4.52 & 2.97 & 0.0733 & 4.374 \\
\hline FeO melt & Guillot 27 & 2000 & 4.25 & 3.10 & 0.0552 & 3.292 \\
\hline FeO melt & $\mathrm{Seo}^{28}$ & 2000 & 3.87 & 2.96 & 0.0618 & 3.688 \\
\hline $\mathrm{FeO}$ melt & Belashchenko 45 & 2400 & 4.6 & 3.02 & 0.0692 & 4.129 \\
\hline
\end{tabular}

The cut-off distances were determined as the average of three criteria, i.e. the first minimum in $g_{i j}(r)$, the first minimum in $r^{2} g_{i j}(r)$ and a fixed cut-off value. The fixed cut-off distances were determined by the mean values of several MD simulations performed using various potentials. MD simulation temperatures are either $2000 \mathrm{~K}$ (closest $T$ step to the highest experimentally measured $T$ ), or else are the lowest liquid temperature simulated prior to the onset of crystallization.

where $\mathrm{Mg}^{2+}$ has only a slightly smaller ionic radius than $\mathrm{Fe}^{2+}$. In the fayalite system, Alderman et al. ${ }^{25}$ found $n_{\mathrm{FeO}}=4.4$ by x-ray diffraction, in reasonable agreement with Ramo and Stixrude ${ }^{23}$. Also values of 4.5 (Sun et al. ${ }^{26}$ ) and 4.7 (Guillot et al. ${ }^{27}$ ) have been predicted using classical MD simulations. Classical MD calculations of molten $\mathrm{FeO}$ by Seo et al. ${ }^{28}$ predict $n_{\mathrm{FeO}}=4.2$, and are able to reproduce transport properties of the $\mathrm{FeO}-\mathrm{SiO}_{2}$ system, although the model density is significantly lower than experiments would suggest ${ }^{29}$. To explore this further, we have carried out a series of classical $\mathrm{MD}$ simulations of molten $\mathrm{FeO}$ using seven published inter-atomic pair potential sets (see Table 2 and Supplementary Table S1 and Figs. S6-S8) and found the Guillot and Sator fayalite potential ${ }^{27}$ to be in the best (but not complete) agreement with the expected density and our experimental diffraction data, with $n_{\mathrm{Fe} 2+-\mathrm{O}}=4.8$, and four- and five-fold $\mathrm{Fe}-\mathrm{O}$ polyhedral units dominating. However, no classical interatomic potential available for mixed valence iron oxides in the literature was found to reproduce the trend observed in Fig. 3.

A deeper understanding of the relative changes in $n_{\mathrm{FeO}}$ can be obtained from an interrogation of the average coordination numbers of $n_{\mathrm{Fe} 2+\mathrm{O}}$ and $n_{\mathrm{Fe} 3+\mathrm{O}}$. The coordination numbers of $\mathrm{Fe}^{2+}-\mathrm{O}$ and $\mathrm{Fe}^{3+}-\mathrm{O}$ in our EPSR models are similar to one another (and mostly invariant with temperature), similar to XANES findings in iron silicate glasses ${ }^{18}$, as both are found to increase with $\mathrm{Fe}^{3+} / \Sigma \mathrm{Fe}$, see Fig. $3 \mathrm{~b}$. Moreover, our EPSR models show that liquid $\mathrm{FeO}_{x}$ primarily consists of 4-, 5- and 6-fold coordinated $\mathrm{Fe}^{2+}$ and $\mathrm{Fe}^{3+}$ atoms, and their relative populations vary with $\mathrm{Fe}^{3+} / \Sigma \mathrm{Fe}$ (Fig. 4). No evidence was found for a bimodal $\mathrm{FeO}_{4}$ and $\mathrm{FeO}_{6}$ distribution in the liquid. Instead, a substantial amount of $\mathrm{Fe}^{3+}(38-49 \%)$ and $\mathrm{Fe}^{2+}(26-41 \%)$ are found in 5-fold coordination indicating that this is a dominant species in all $\mathrm{FeO}_{x}$ melts. For ferrous iron, our EPSR models show $\mathrm{Fe}^{2+}$ predominantly occupies 4 - and 5-coordinated sites, which is consistent with other divalent cations e.g. $\mathrm{Ni}^{2+}, \mathrm{Fe}^{2+}$, and $\mathrm{Mg}^{2+}$ in molten silicates ${ }^{30}$. For ferric iron, $\mathrm{Fe}^{3+}, 4$-fold and 5-fold polyhedra also dominate at low $\mathrm{Fe}^{3+} / \Sigma \mathrm{Fe}$, but for $\mathrm{Fe}^{3+} / \Sigma \mathrm{Fe}>40 \%$ the number of 6 -fold $\mathrm{Fe}^{3+}$ increases and the number of 4 -fold $\mathrm{Fe}^{3+}$ decreases. This is opposite to the trend reported for binary silicate melts by Mysen ${ }^{15}$, which indicated $n_{\mathrm{Fe} 3+-\mathrm{O}}$ decreases from 6 to 4 with increasing $\mathrm{Fe}^{3+} / \Sigma \mathrm{Fe}$. In addition, it is a more complex scenario than that proposed by Hayashi et al. ${ }^{17}$ who only considered the existence of tetrahedral and octahedral $\mathrm{Fe}-\mathrm{O}$ units in sodium-iron-silicate melts.

An alternative view of the change in liquid structure with redox can be obtained through the extraction of the oxygen-iron coordination number $n_{\mathrm{OFe}}$. In Fig. $3 \mathrm{c}, \mathrm{n}_{\mathrm{OFe}}$ tends toward $\sim 3.5$ in pure $\mathrm{O}_{2}$ gas close to that found in $\gamma-\mathrm{Fe}_{2} \mathrm{O}_{3}$, but this increases only slightly to $\sim 4.5$ around $\mathrm{FeO}$ (compared to 6 in the crystalline phase). An analysis of the fraction of OFe coordination species with $\mathrm{Fe}^{3+} / \Sigma \mathrm{Fe}$ in Fig. $4 \mathrm{c}$ in our EPSR models shows a dramatic effect. We find that the dominant $\mathrm{OFe}_{4}$ units account for approximately half the species in the melt and this remains relatively constant with $\mathrm{Fe}^{3+} / \Sigma \mathrm{Fe}$. For $\mathrm{Fe}^{3+}$ rich melts $\mathrm{OFe}_{3}$ units account for almost all of the remaining oxygen connectivity. As the availability of oxygen decreases and the percentage of $\mathrm{Fe}^{2+}$ increases, the $\mathrm{OFe}_{3}$ units are partially replaced by $\mathrm{FeO}_{5}$ units.

Finally, we consider the relationship between the presence of various local atomic structural units and the physical properties of liquid iron oxide slags. In binary ferrite melts it has been suggested that the atomic fraction of $\mathrm{Fe}^{3+} \mathrm{O}_{4}$ is the main factor in controlling the viscosity and the abundance of $\mathrm{Fe}^{2+}$ and $\mathrm{Fe}^{3+} \mathrm{O}_{6}$ units are main contributors to the electrical conductivity ${ }^{31}$. In addition, chemical reaction rates in the iron and steel making process are determined by concentrations and activities, where the activity is dependent upon bond strengths in different coordination environments ${ }^{17}$. However, a comparison of our diffraction data with a survey of classical MD simulations performed using various potentials in the literature has revealed the shortcomings of many interatomic potentials across the compositional range of $\mathrm{FeO}_{x}$ melts, see Supplementary Fig. S7. Hence more sophisticated theoretical work and/or ab initio simulations are necessary to elucidate the precise ratios of 4-, 5- and 6-fold coordinated $\mathrm{Fe}^{2+}-\mathrm{O}$ and $\mathrm{Fe}^{3+}-\mathrm{O}$ in liquid $\mathrm{FeO}_{x}$, particularly in order to understand transport properties, and to address chargetransfer and small-polaron conductance phenomena. In fact, during the writing of this article we note that two ab initio molecular dynamics simulations on $\mathrm{FeO}_{x}$-bearing silicate melts have been published ${ }^{32,33}$. It is anticipated that our experimental pair distribution functions for molten iron oxides presented herein will provide ambient-pressure benchmarks to test models relevant to a wide range of industrial and natural processes.

\section{Methods}

Levitation and high-energy $\mathbf{X}$-ray diffraction experiments. We formed powdered $\mathrm{Fe}_{2} \mathrm{O}_{3}$ (purity 99.995\%) into roughly $3 \mathrm{~mm}$ diameter spheres using a laser hearth melter in the air. Weighed samples were floated in a $200-500 \mathrm{~mL} / \mathrm{min}$ stream of gas, using a conical nozzle aerodynamic levitator in an enclosure ${ }^{25}$, and heated from above using a $400 \mathrm{~W} \mathrm{CO}$ laser (Synrad Firestar i401). The droplet surface temperature was measured using $0.9 \mu \mathrm{m}$ wavelength optical pyrometry (Chino IR-CAS) sighted onto the region of the sample where the X-ray measurements were made. A constant spectral emissivity of $\varepsilon_{\lambda}=0.92$ was assumed for 

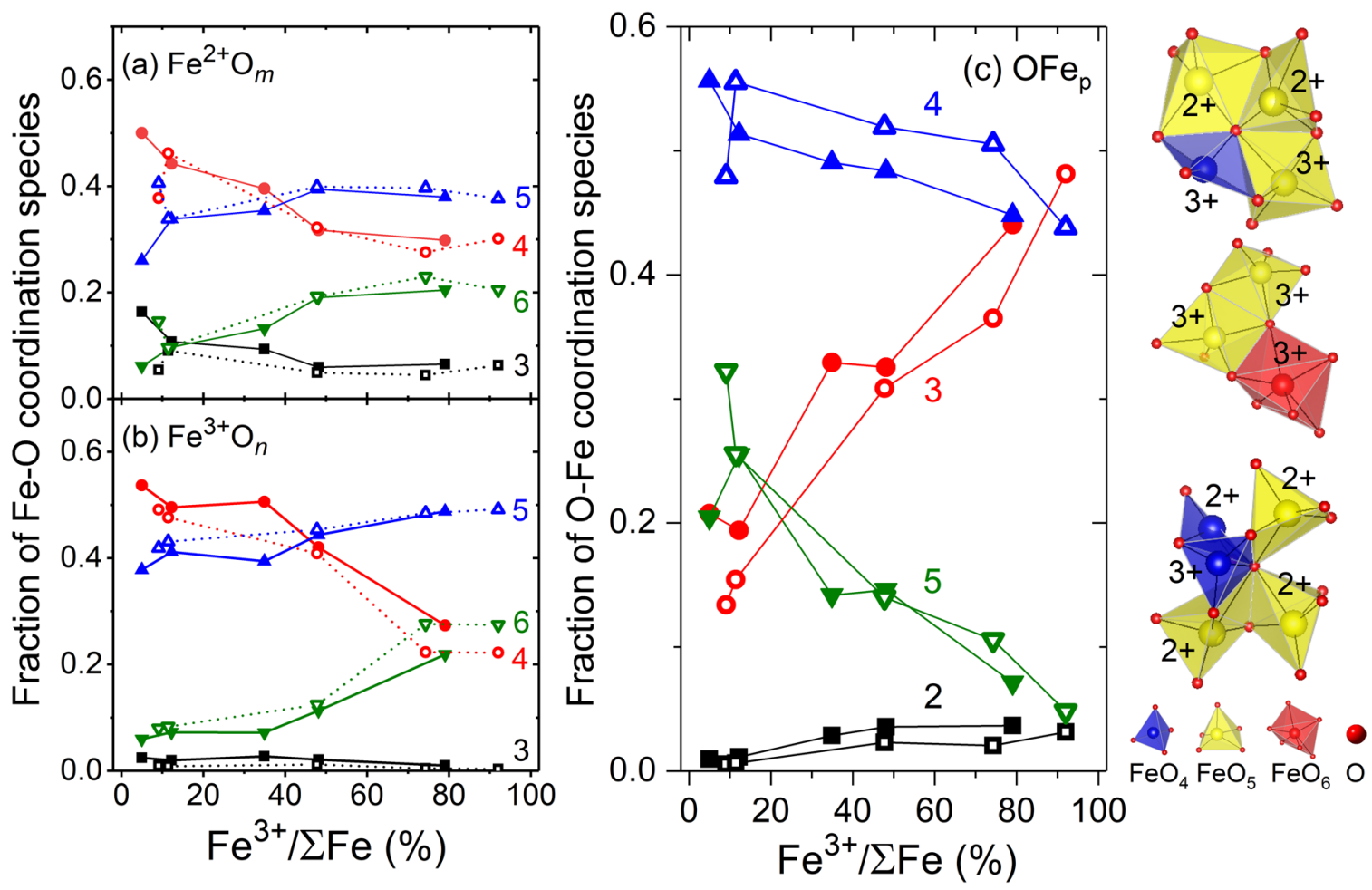

Fig. 4 The distribution of polyhedra in our EPSR models. a Fe ${ }^{2+} \mathrm{O}_{m} \mathbf{b} \mathrm{Fe}^{3+} \mathrm{O}_{n}$ units (where $\left.m, n=3,4,5,6\right)$ and $\mathbf{c}$ OFe $\mathrm{p}_{\mathrm{p}}$ units (where $\left.p=2,3,4,5\right)$ from EPSR models at $1973 \mathrm{~K}$ (solid symbols) and $1673 \mathrm{~K}$ (open symbols), as a function of $\mathrm{Fe}^{3+} / \Sigma \mathrm{Fe}(\%)$ (Calculated using equation 12 of ref. ${ }^{35}$ ). $n_{\mathrm{FeO}}$ and $n_{\mathrm{OFe}}$ were determined by the average of the three cut-off criteria. The clusters on the right correspond to representative $\mathrm{OFe}_{4}$, $\mathrm{OFe}_{3}$, and $\mathrm{OFe}{ }_{5}$ units taken from the EPSR models.

correcting the apparent temperatures and the accuracy of the pyrometer was $\sim 1 \%$ for temperatures in the range $1773-1973 \mathrm{~K}$. The oxygen partial pressure, $p\left(\mathrm{O}_{2}\right)$, experienced by the sample was controlled using different levitation gas mixtures, either 99CO: $1 \mathrm{CO}_{2}, 50 \mathrm{CO}: 50 \mathrm{CO}_{2}, \mathrm{CO}_{2}$ (all $\mathrm{CO}: \mathrm{CO}_{2}$ mixtures were $5 \%$ with a balance of $95 \% \mathrm{Ar}$ ), $99.9 \% \mathrm{Ar}: 0.1 \% \mathrm{O}_{2}$ or pure $\mathrm{O}_{2}$, leading to a range of $\mathrm{Fe}^{3+} / \Sigma \mathrm{Fe}$ at equilibrium. The $p\left(\mathrm{O}_{2}\right)$ were calculated by standard methods ${ }^{34}$, based on the measured droplet surface temperatures and the $\mathrm{Fe}^{3+} / \Sigma \mathrm{Fe}$ ratio was estimated using equation 12 from Jayasuriya et al. ${ }^{35}$, which has previously been found ${ }^{13}$ to be in accord with the molten iron oxide data of Darken and Gurry ${ }^{36}$. A detailed evaluation of the effect of errors in the calculated values of $\mathrm{Fe}^{3+} / \Sigma \mathrm{Fe}$ is described in the uncertainty section and Supplementary Fig. S5.

High energy X-ray diffraction was performed at the Advanced Photon Source beamline 6-ID-D, (Argonne, IL, USA) using an incident X-ray beam of wavelength $0.123538 \AA(100.36 \mathrm{keV})$. A Perkin Elmer XRD1621 area detector was placed $\sim 338$ $\mathrm{mm}$ downstream of the sample and calibrated using a $\mathrm{CeO}_{2}$ powder standard (NIST) to provide a wide $Q$ range of $0.5-25.0 \AA^{-1}$. The $\mathrm{x}$-ray beam was centered on the top $200 \mu \mathrm{m}$ of the sample sphere to align with the laser beam and pyrometry measurement and avoid scattering from the levitator components. Before heating a sample, the chamber was purged with the selected process gas for $20 \mathrm{~min}$. The levitated sample was then heated to a temperature just above its melting point, and held for 10-20 s to ensure complete melting. Diffraction patterns were collected for $40 \mathrm{~s}$ each in $\sim 100 \mathrm{~K}$ steps in a sequence of decreasing temperatures from $1973 \mathrm{~K}$ to at least $1673 \mathrm{~K}$. Only scattered X-ray data from the top half of the Debye-Scherrer cone were used in the analysis to avoid significant attenuation corrections. The $\mathrm{x}$-ray total structure factor $S(Q)$ and the corresponding differential pair-distribution function $D$ $(r)=4 \pi \rho r[G(r)-1]$ as a function of temperature and $p\left(\mathrm{O}_{2}\right)$ were extracted. Details of the high-energy X-ray analysis used have previously been described by Shi et al. ${ }^{37}$ from samples prepared in a laser hearth melter ${ }^{38}$. Three-dimensional models describing the atomic structure were obtained using $\mathrm{EPSR}^{39}$. The $\mathrm{Fe}^{3+} / \Sigma \mathrm{Fe}$ ratio was estimated using equation 12 from Jayasuriya et al. ${ }^{35}$, which was found to be in accord with the molten iron oxide data of Darken and Gurry ${ }^{36}$.

\footnotetext{
Atomistic modeling

Empirical potential structure refinement modeling. $\operatorname{EPSR}^{39}$ were used to obtain atomistic models of liquid $\mathrm{FeO}_{x}$ based on the high-energy x-ray diffraction data. The EPSR simulations were performed on $\sim 6000$ ions within a cubic box under periodic boundary conditions, and the temperature dependent densities fixed using the equations of Hara et al. ${ }^{29}$. A Lennard-Jones reference potential with $\mathrm{Fe}^{3+}$ and $\mathrm{O}^{2-}$ parameters from Weigel et al. ${ }^{40}$ was used. For $\mathrm{Fe}^{2+}$, the reference potential parameters are given in Table 1, and were modified only slightly from those of $\mathrm{Fe}^{3+}$ by
}

comparing initial Monte Carlo simulation predictions of the Fe-O bond length distributions to the diffraction data. The starting configuration was built according to the calculated $\mathrm{Fe}^{3+} / \Sigma \mathrm{Fe}$ ratio ${ }^{35}$ and, following initial Monte Carlo equilibration, the empirical potential term was refined to improve agreement with scattering data, with the maximum allowed energy amplitude set to $\sim 30 \%$ of initial model energy. Once the goodness-of-fit parameter was minimized, structural data were collected over ensembles of at least 2000 configurations. The resulting EPSR fits were in excellent agreement with the high energy X-ray diffraction data shown in Fig. 2, see Fig. S1.

Classical molecular dynamics simulations. Classical molecular dynamics (MD) simulations with $0 \% \mathrm{Fe}^{3+}$ were performed using the DL POLY package ${ }^{41}$ on a system containing $\sim 6000$ atoms. Several published potentials ${ }^{27,28,42-45}$ were tested. The results of Monte Carlo simulations under the EPSR reference potentials were used as starting configurations for the MD simulations, which were conducted either in the canonical (NVT) or the isothermal-isobaric (NPT) ensemble, using a Hoover-Nose thermostat or thermostat-barostat, at $P=1 \mathrm{~atm}$ and various temperatures. A time step of $1.0 \mathrm{fs}$ was selected, with the first 25000 steps used for equilibration, and particle trajectories typically integrated over a further 50,000 steps (production runs) at each temperature point. The starting temperature was $2700 \mathrm{~K}$ and the systems were cooled stepwise in $100 \mathrm{~K}$ steps down to $300 \mathrm{~K}$. In some cases $\left(\mathrm{Fe}^{2+}\right.$-rich) crystallization was observed, and in all other cases glass formation occurred. The effect of $\mathrm{Fe}^{3+} / \Sigma \mathrm{Fe}$ on the liquid structure was also investigated using the Teter and Guillot pair potentials ${ }^{27,42}$

\section{Data availability}

The total X-ray structure factors and their corresponding pair distribution functions are provided in the supplementary information.

Received: 21 May 2020; Accepted: 6 September 2020; Published online: 05 November 2020

\section{References}

1. Allanore, A., Yin, L. \& Sadoway, D. R. A new anode material for oxygen evolution in molten oxide electrolysis. Nature. 497, 353-356 (2013).

2. Zhang, H., Fu, L., Qi, J. \& Xuan, W. Physicochemical properties of the molten iron-rich slags related to the copper recovery. Metall. Mater. Trans. B Process Metall. Mater. Process. Sci. 50, 1852-1861 (2019). 
3. Jackson, W. E. et al. High-temperature XAS study of $\mathrm{Fe}_{2} \mathrm{SiO}_{4}$ liquid: Reduced coordination of ferrous iron. Science. 262, 229-233 (1993).

4. Wicks, J. K., Jackson, J. M. \& Sturhahn, W. Very low sound velocities in ironrich $(\mathrm{Mg}, \mathrm{Fe}) \mathrm{O}$ : Implications for the core-mantle boundary region. Geophys. Res. Lett. 37, L15304 (2010).

5. Vercamer, V. Spectroscopic and Structural Properties of Iron in Silicate Glasses. (Université Pierre et Marie Curie - Paris VI, 2016., 2016).

6. Di Genova, D., Vasseur, J., Hess, K. U., Neuville, D. R. \& Dingwell, D. B. Effect of oxygen fugacity on the glass transition, viscosity and structure of silica- and iron-rich magmatic melts. J. Non. Cryst. Solids 470, 78-85 (2017).

7. Wilke, M. Fe in magma - an overview. Ann. Geophys. 48, 609-617 (2005).

8. Rossano, S. et al. ${ }^{57} \mathrm{Fe}$ Mossbauer spectroscopy of tektites. Phys. Chem. Miner. 26, 530-538 (1999).

9. Waychunas, G. A., Brown, G. E., Ponader, C. W. \& Jackson, W. E. Evidence from X-ray absorption for network-forming $\mathrm{Fe}^{2+}$ in molten alkali silicates. Nature 332, 251-253 (1988).

10. Waseda, Y. \& Toguri, J. M. The Structure of the Molten $\mathrm{FeO}-\mathrm{SiO}_{2}$ System. Metall. Trans. B 9, 595-601 (1978).

11. Waseda, Y. \& Shiraishi, Y. Structure of molten $\mathrm{FeO}$ at $1420^{\circ} \mathrm{C}$. Trans. Iron Steel Inst. Japan 18, 783-784 (1978).

12. Hennet, L. et al. X-Ray diffraction and near edge studies of iron oxides and alumina at high temperatures using aerodynamic levitation and laser heating. Jpn. J. Appl. Phys. 38, 115 (1999).

13. Alderman, O. L. G. et al. Iron K-edge X-ray absorption near-edge structure spectroscopy of aerodynamically levitated silicate melts and glasses. Chem. Geol. 453, 169-185 (2017).

14. Calas, G. \& Petiau, J. Coordination of iron in oxide glasses through highresolution K-edge spectra: Information from the pre-edge. Solid State Commun. 48, 625-629 (1983).

15. Mysen, B. O. The structural behavior of ferric and ferrous iron in aluminosilicate glass near meta-aluminosilicate joins. Geochim. Cosmochim. Acta 70, 2337-2353 (2006).

16. Pargamin, L., Lupis, C. H. P. \& Flinn, P. A. Mössbauer analysis of the distribution of iron cations in silicate slags. Metall. Trans. 3, 2093-2105 (1972).

17. Hayashi, M., Horita, K., Endo, R., Watanabe, T. \& Susa, M. Effect of coordination structure of iron ions on iron oxide activities in $\mathrm{Na}_{2} \mathrm{O}-\mathrm{SiO}_{2}-\mathrm{FeO}-\mathrm{Fe}_{2} \mathrm{O}_{3}$ melts. ISIJ Int 59, 1744-1751 (2019).

18. Farges, F. et al. The effect of redox state on the local structural environment of iron in silicate glasses: a combined XAFS spectroscopy, molecular dynamics, and bond valence study. J. Non. Cryst. Solids 344, 176-188 (2004).

19. Haskins, J. B., Stern, E. C., Bauschlicher, C. W. \& Lawson, J. W. Thermodynamic and transport properties of meteor melt constituents from ab initio simulations: $\mathrm{MgSiO}_{3}, \mathrm{SiO}_{2}$, and MgO. J. Appl. Phys. 125, 235102 (2019).

20. Holmström, E. \& Stixrude, L. Spin crossover in liquid ( $\mathrm{Mg}, \mathrm{Fe}) \mathrm{O}$ at extreme conditions. Phys. Rev. B 93, 195142 (2016).

21. Wright, A. C. et al. The environment of $\mathrm{Fe}^{2+} / \mathrm{Fe}^{3+}$ cations in a soda-lime-silica glass. Phys. Chem. Glas. Eur. J. Glas. Sci. Technol. Part B 55, 243-252 (2014).

22. Hidayat, T., Shishin, D., Jak, E. \& Decterov, S. A. Thermodynamic reevaluation of the Fe-O system. Calphad. 48, 131-144 (2015).

23. Ramo, D. M. \& Stixrude, L. Spin crossover in $\mathrm{Fe}_{2} \mathrm{SiO}_{4}$ liquid at high pressure. Geophys. Res. Lett. 41, 4512-4518 (2014)

24. Karki, B. B., Maharjan, C. \& Ghosh, D. B. Thermodynamics, structure, and transport properties of the $\mathrm{MgO}-\mathrm{Al}_{2} \mathrm{O}_{3}$ liquid system. Phys. Chem. Miner. 46, 501-512 (2019).

25. Alderman, O. L. G. et al. Local structural variation with oxygen fugacity in $\mathrm{Fe}_{2} \mathrm{SiO}_{4+\mathrm{x}}$ fayalitic iron silicate melts. Geochim. Cosmochim. Acta 203, 15-36 (2017).

26. Sun, Y. et al. Transport properties of $\mathrm{Fe}_{2} \mathrm{SiO}_{4}$ melt at high pressure from classical molecular dynamics: implications for the lifetime of the magma ocean. J. Geophys. Res. Solid Earth 123, 3667-3679 (2018).

27. Guillot, B. \& Sator, N. A computer simulation study of natural silicate melts. Part I: Low pressure properties. Geochim. Cosmochim. Acta 71, 1249-1265 (2007).

28. Seo, W. G. \& Tsukihashi, F. Thermodynamic and structural properties for the $\mathrm{FeO}-\mathrm{SiO}_{2}$ system by using molecular dynamics calculation. Mater. Trans. 46, 1240-1247 (2005).

29. Hara, S., Irie, K., Gaskell, D. R. \& Ogino, K. Densities of melts in the $\mathrm{FeO}-\mathrm{Fe}_{2} \mathrm{O}_{3}-\mathrm{BaO}$ system. Trans. Jpn Inst. Met. 29, 990-1002 (1988).

30. Farges, F. \& Brown, G. E. An empirical model for the anharmonic analysis of high-temperature XAFS spectra of oxide compounds with applications to the coordination environment of $\mathrm{Ni}$ in $\mathrm{NiO}, \gamma-\mathrm{Ni}_{2} \mathrm{SiO}_{4}$ and Ni-bearing $\mathrm{Na}$ disilicate glass and melt. Chem. Geol. 128, 93-106 (1996).

31. Sumita, S., Morinaga, K. \& Yanagase, T. Physical properties and structure of binar ferrite melts. Trans. Jpn Inst. Met. 24, 35-41 (1983).
32. Ghosh, D. B. \& Karki, B. B. Effects of valence and spin of Fe in $\mathrm{MgSiO}_{3}$ melts: Structural insights from first-principles molecular dynamics simulations. Geochim. Cosmochim. Acta. 279, 108-118 (2020).

33. Solomatova, N. V. \& Caracas, R. Pressure-induced coordination changes in a pyrolitic silicate melt from ab initio molecular dynamics simulations. J. Geophys. Res. Solid Earth 124, 11232-11250 (2019).

34. Fegley, B. Practical Chemical Thermodynamics for Geoscientists. Practical Chemical Thermodynamics for Geoscientists (Elsevier Inc., 2013). https://doi. org/10.1016/C2009-0-22615-8.

35. Jayasuriya, K. D., O’Neill, H. S. C., Berry, A. J. \& Campbell, S. J. A Mössbauer study of the oxidation state of Fe in silicate melts. Am. Mineral. 89, 1597-1609 (2004).

36. Darken, L. S. \& Gurry, R. W. The system iron-oxygen. II. Equilibrium and thermodynamics of liquid oxide and other phases. J. Am. Chem. Soc. 68 , 798-816 (1946).

37. Shi, C. et al. The structure of amorphous and deeply supercooled liquid alumina. Front. Mater 6, 38 (2019).

38. Richard Weber, J. K., Felten, J. J. \& Nordine, P. C. Laser hearth melt processing of ceramic materials. Rev. Sci. Instrum. 67, 522-524 (1996)

39. Soper, A. K. Partial structure factors from disordered materials diffraction data: an approach using empirical potential structure refinement. Phys. Rev. B - Condens. Matter Mater. Phys 72, 104204 (2005).

40. Weigel, C., Cormier, L., Calas, G., Galoisy, L. \& Bowron, D. T. Intermediaterange order in the silicate network glasses $\mathrm{NaFe}_{\mathrm{x}} \mathrm{Al}_{1-\mathrm{x}} \mathrm{Si}_{2} \mathrm{O}_{6}(\mathrm{x}=0,0.5,0.8,1)$ : a neutron diffraction and empirical potential structure refinement modeling investigation. Phys. Rev. B Condens. Matter Mater. Phys 78, 064202 (2008).

41. Smith, W. \& Forester, T. R. DL-POLY-2.0: a general-purpose parallel molecular dynamics simulation package. J. Mol. Graph. 14, 136-141 (1996).

42. Yang, Z., Wang, B. \& Cormack, A. N. The local structure of $\mathrm{Fe}$ in $\mathrm{Li}(\mathrm{Al}, \mathrm{Fe})$ $\mathrm{Si}_{2} \mathrm{O}_{6}$ glasses from molecular dynamics simulations. J. Non. Cryst. Solids $\mathbf{4 4 4}$, $16-22(2016)$

43. Pedone, A., Malavasi, G., Menziani, M. C., Cormack, A. N. \& Segre, U. A new self-consistent empirical interatomic potential model for oxides, silicates, and silicas-based glasses. J. Phys. Chem. B 110, 11780-11795 (2006).

44. Rossano, S., Ramos, A. Y. \& Delaye, J. M. Environment of ferrous iron in $\mathrm{CaFeSi}_{2} \mathrm{O}_{6}$ glass; contributions of EXAFS and molecular dynamics. J. Non. Cryst. Solids 273, 48-52 (2000).

45. Belashchenko, D. K. Computer simulation of non-crystalline oxides $\mathrm{MeO}$ and $\mathrm{Me}_{2} \mathrm{O}_{3}$. J. Non. Cryst. Solids 205-207, 212-215 (1996).

\section{Acknowledgements}

We would like to thank Dr. L.B. Skinner for initiating this work. C.S. gratefully acknowledges financial support from the China Scholarship Council (CSC No. 201706890053). This research used resources of the Advanced Photon Source, the U.S Department of Energy (DOE) Office of Science User Facility operated for the DOE Office of Science by Argonne National Laboratory under Contract No. DE-AC02-06CH11357. This work was partially funded under DOE grant numbers DE-SC0015241 and DESC0018601.

\section{Author contributions}

C.S. carried out the experiments, analyzed data, performed the EPSR and MD simulations, prepared the paper, and wrote the supplementary information. O.L.G.A. jointly conceived the study, supervised its analysis, and edited the paper, carried out the experiments, analyzed data, supervised the EPSR and MD simulations. A.T. built the instrumentation, carried out the experiments. J.Y. and R.W. jointly conceived the study, built the instrumentation, carried out the experiments, edited the paper. J.Y. jointly conceived the study, edited the paper. C.J.B. jointly conceived the study, supervised its analysis and edited the paper, carried out the experiments, helped analyze the data and interpret the MD simulations.

\section{Competing interests}

The authors declare no competing interests.

\section{Additional information}

Supplementary information is available for this paper at https://doi.org/10.1038/s43246 020-00080-4.

Correspondence and requests for materials should be addressed to C.J.B.

Reprints and permission information is available at http://www.nature.com/reprints

Publisher's note Springer Nature remains neutral with regard to jurisdictional claims in published maps and institutional affiliations. 
(c) (i) Open Access This article is licensed under a Creative Commons Attribution 4.0 International License, which permits use, sharing, adaptation, distribution and reproduction in any medium or format, as long as you give appropriate credit to the original author(s) and the source, provide a link to the Creative Commons license, and indicate if changes were made. The images or other third party material in this article are included in the article's Creative Commons license, unless indicated otherwise in a credit line to the material. If material is not included in the article's Creative Commons license and your intended use is not permitted by statutory regulation or exceeds the permitted use, you will need to obtain permission directly from the copyright holder. To view a copy of this license, visit http://creativecommons.org/ licenses/by/4.0/.

(C) The Author(s) 2020 